\title{
七三八 錄驗實誌雜會究研事醫堂天順
}

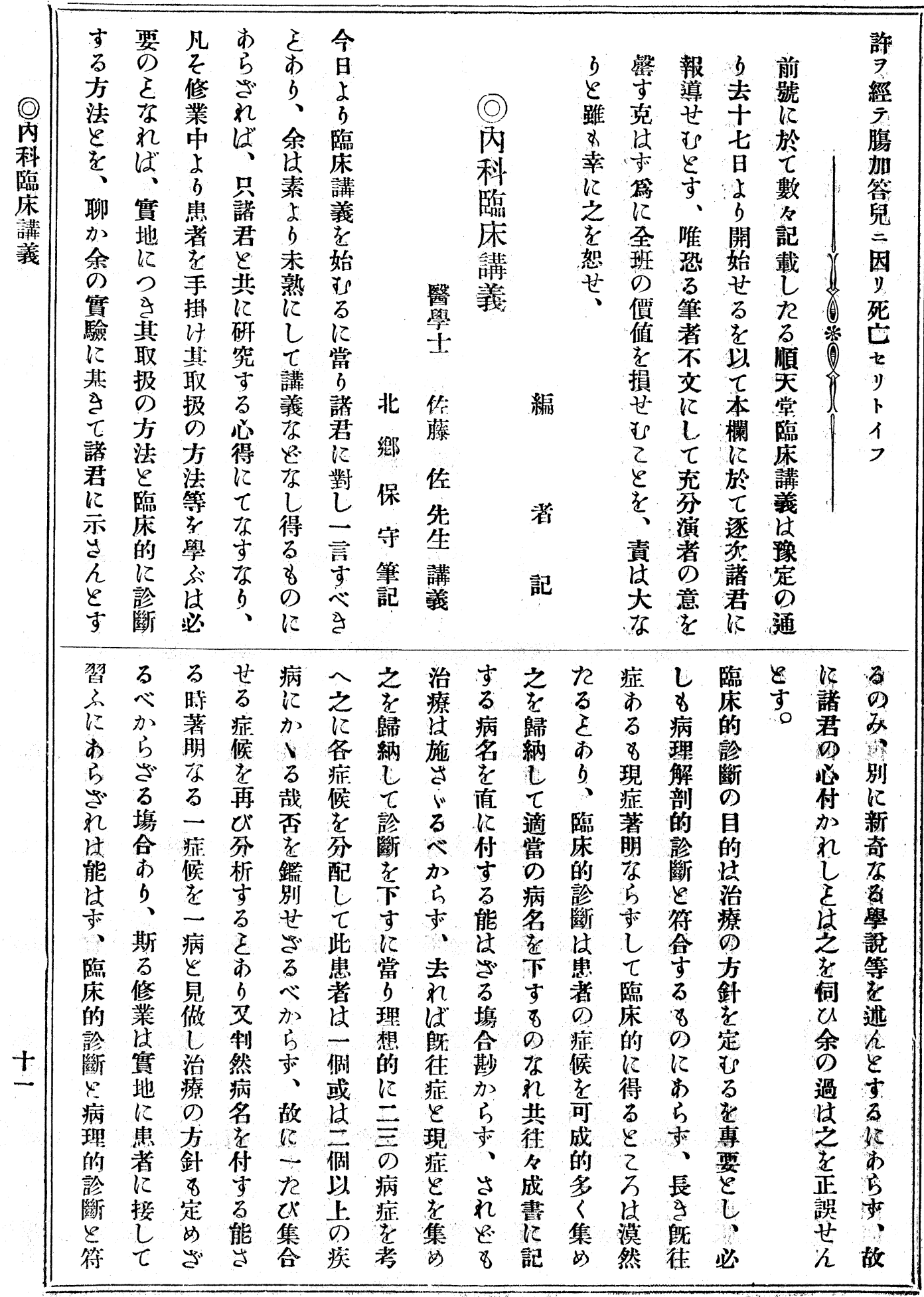


號十三百三第雜誌會笲研事醫堂天順 八三入






\section{九三八 錄驗賽誌雜會究研事醫堂天順}

比に比氏線 3 打 部特皆胸現他當治 5 症

し比し半の打診 $と$ 見縮症に時療れ、

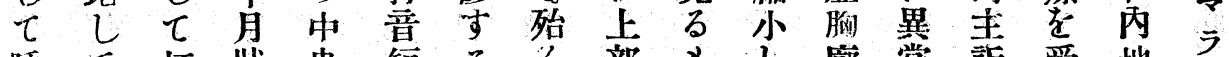

(2) 呼 $\tau$ 打 牀 央短当 $九$ 部 8 影常挀受地

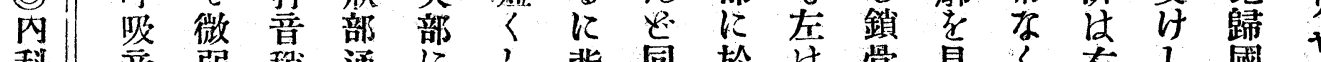

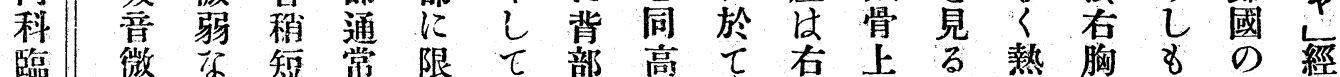

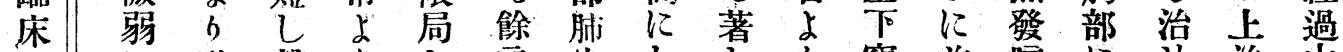

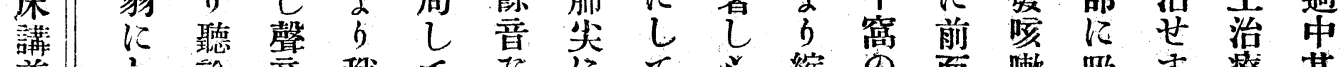

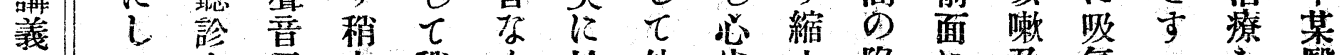

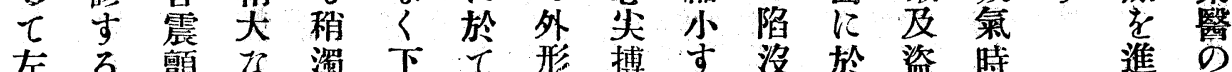

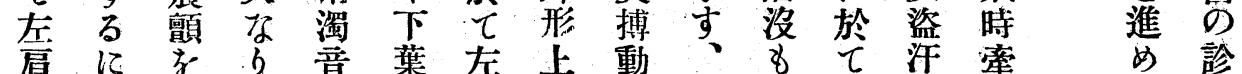

胛前撿前の、方變の呼左右等引引

下後和面著於注化所吸注壮性俄

部共るにして右在連右左し疼東 $b$

及一に於 巳 8 方認不動に连を痛都左

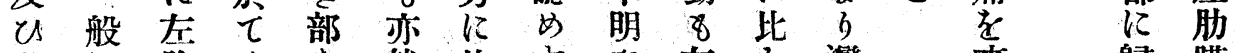

左に胸 \& 然比亦左し灣来歸膜

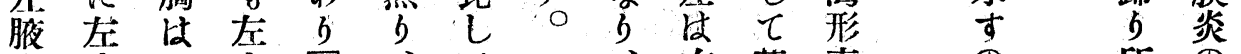

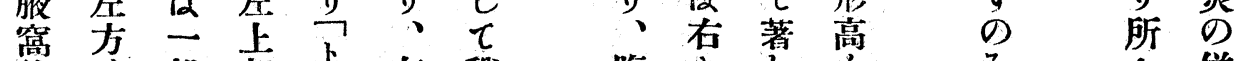

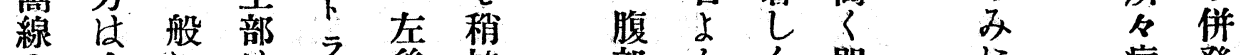

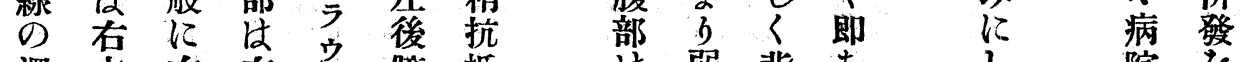

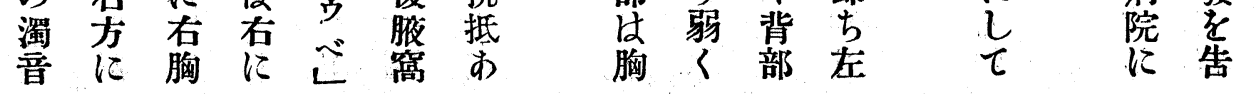

ら橫に能はの膜實みは滲く卡此肩吾部

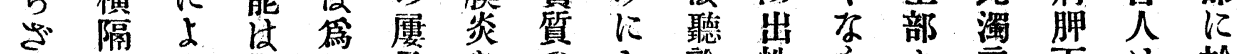

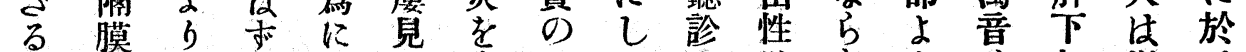

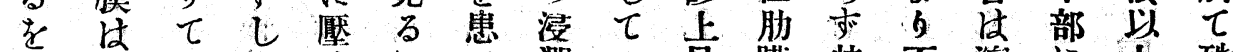

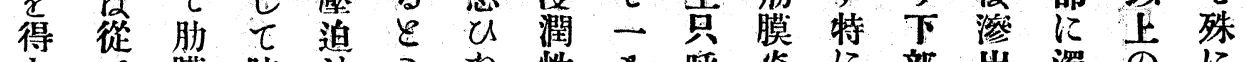

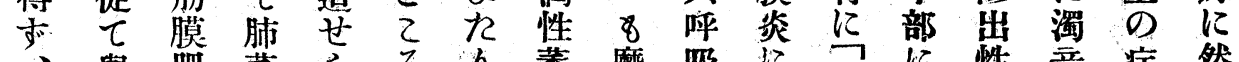

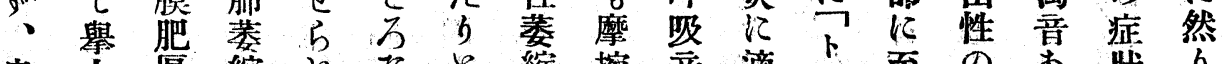

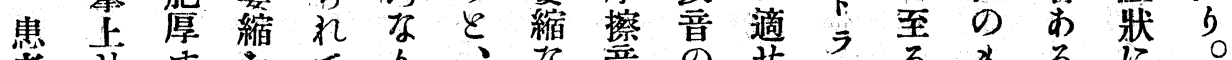

者 せ

胸 望

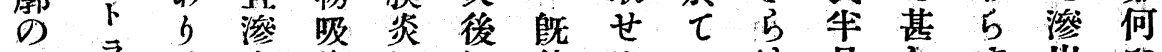

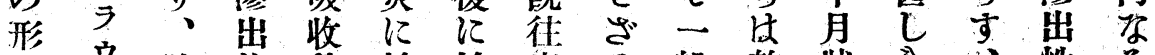

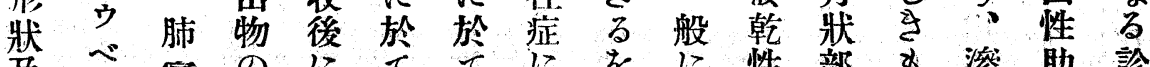

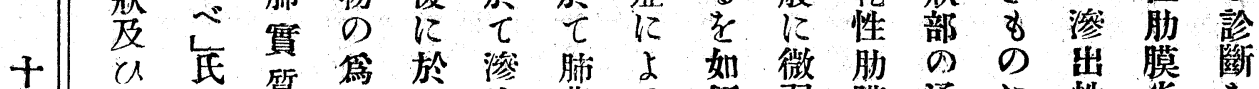

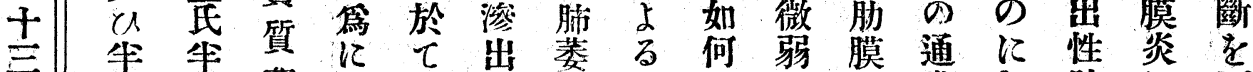

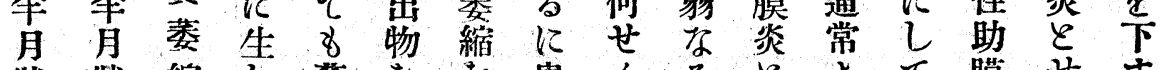

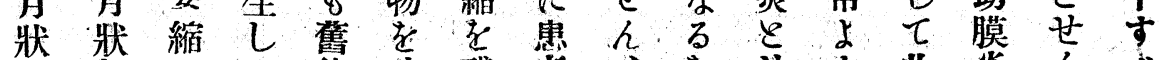

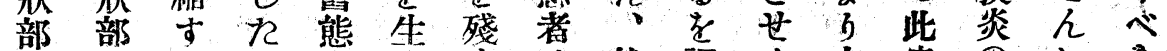

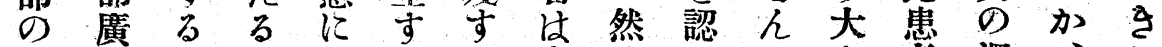

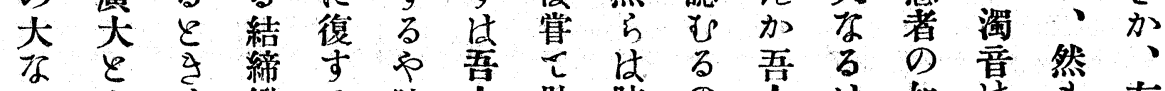

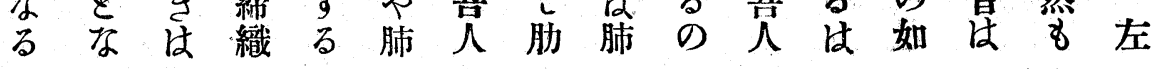




\begin{tabular}{|c|c|c|c|c|c|c|c|c|c|c|c|c|c|c|c|c|}
\hline 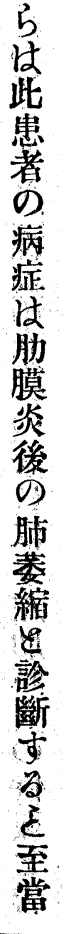 & 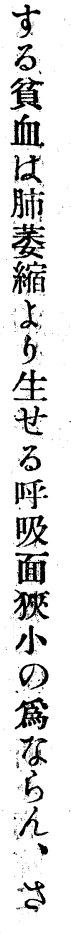 & 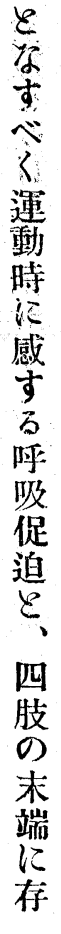 & 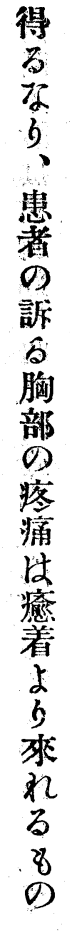 & 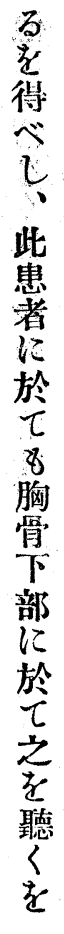 & 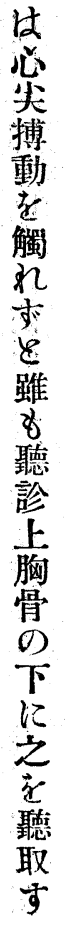 & 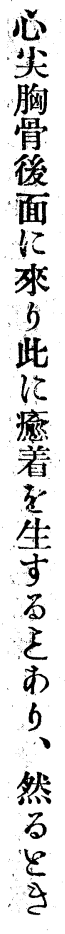 & 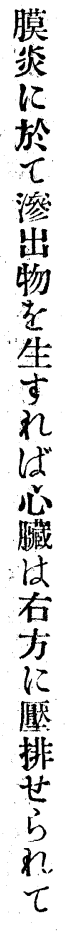 & 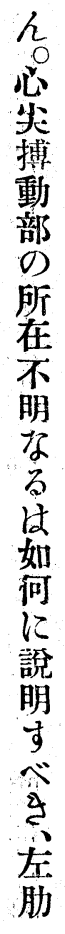 & 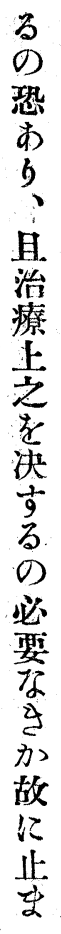 & 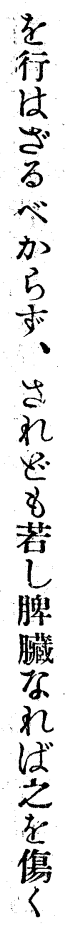 & 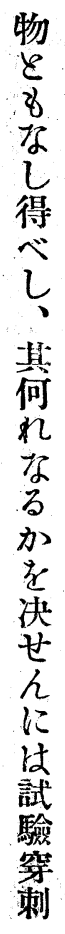 & 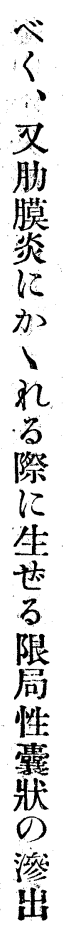 & 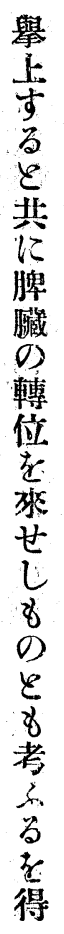 & 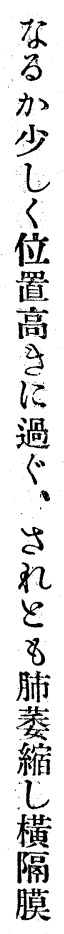 & 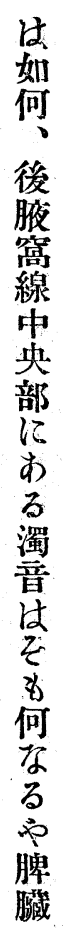 & 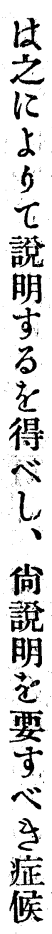 \\
\hline 溪 & 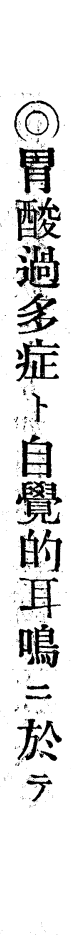 & ) & 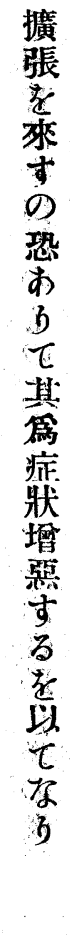 & 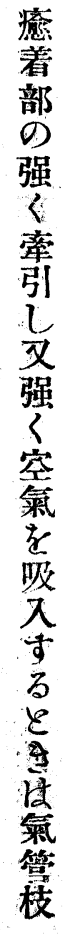 & 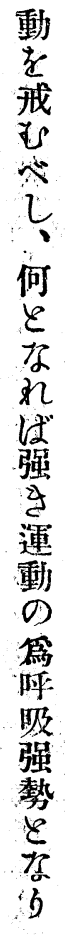 & 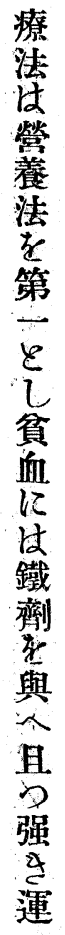 & 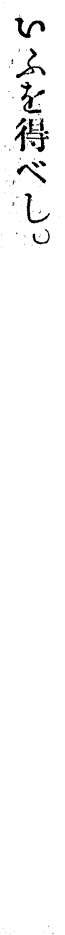 & 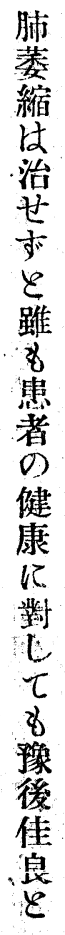 & 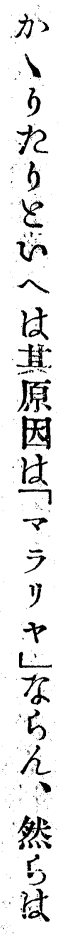 & 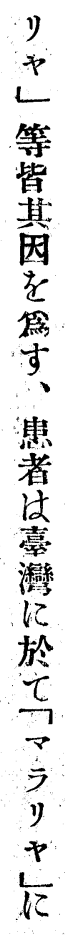 & 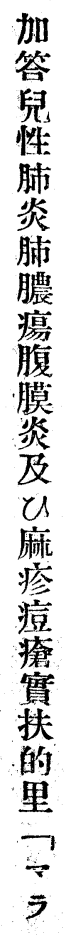 & 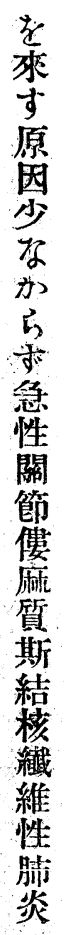 & 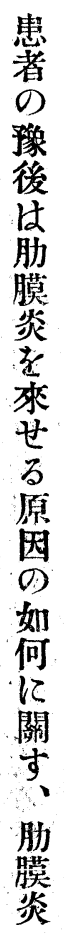 & $\dot{y}$ & 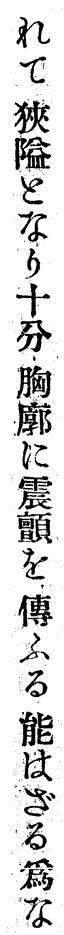 & 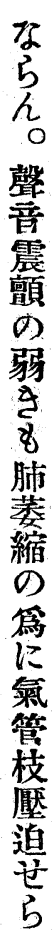 \\
\hline
\end{tabular}

